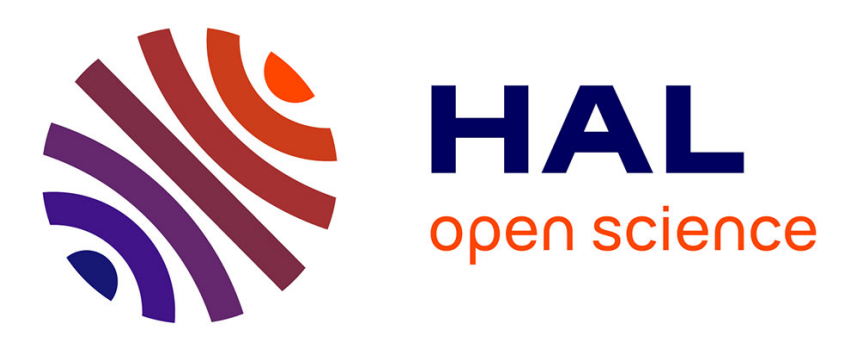

\title{
Games Ready to Use: A Serious Game for Teaching Natural Risk Management
}

Franck Taillandier, Carole Adam

\section{To cite this version:}

Franck Taillandier, Carole Adam. Games Ready to Use: A Serious Game for Teaching Natural Risk Management. Simulation and Gaming, 2018, 49 (4), pp.441-470. 10.1177/1046878118770217 . hal02936161

\section{HAL Id: hal-02936161 https://hal.inrae.fr/hal-02936161}

Submitted on 14 Sep 2020

HAL is a multi-disciplinary open access archive for the deposit and dissemination of scientific research documents, whether they are published or not. The documents may come from teaching and research institutions in France or abroad, or from public or private research centers.
L'archive ouverte pluridisciplinaire HAL, est destinée au dépôt et à la diffusion de documents scientifiques de niveau recherche, publiés ou non, émanant des établissements d'enseignement et de recherche français ou étrangers, des laboratoires publics ou privés. 


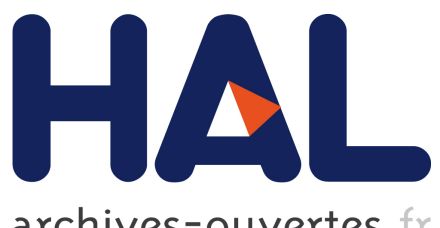

archives-ouvertes

\section{Games ready to use: A serious game for teaching natural risk management}

Carole Adam, Franck Taillandier

\section{To cite this version:}

Carole Adam, Franck Taillandier. Games ready to use: A serious game for teaching natural risk management. Simulation and Gaming, SAGE Publications, 2018. halshs-02115959

\section{HAL Id: halshs-02115959 https://halshs.archives-ouvertes.fr/halshs-02115959}

Submitted on 30 Apr 2019

HAL is a multi-disciplinary open access archive for the deposit and dissemination of scientific research documents, whether they are published or not. The documents may come from teaching and research institutions in France or abroad, or from public or private research centers.
L'archive ouverte pluridisciplinaire HAL, est destinée au dépôt et à la diffusion de documents scientifiques de niveau recherche, publiés ou non, émanant des établissements d'enseignement et de recherche français ou étrangers, des laboratoires publics ou privés. 


\title{
A serious game for teaching natural risk management
}

\author{
Carole Adam $\quad$ Franck Taillandier
}

April 30, 2019

\begin{abstract}
Risk management has become an essential skill for civil engineers. Teaching risk management to engineering students is therefore crucial, but is also challenging: it looks too abstract to students, and practical works are complex and expensive to organise. It also involves interconnected mechanisms coupling human and technical aspects, that are difficult to explain. In order to support risk management teaching, we propose SPRITE, an agent-based serious game using a concrete case study which is exemplary in terms of risk management: the coastal floods on the Oleron Island (France). SPRITE places the player (student) in the role of a local councillor of the Oleron Island, who must ensure the safety and well-being of the island residents, while maximising performance w.r.t. economic and environmental issues, in a context of coastal flood risk. SPRITE is the central piece of a pedagogical sequence which is actually used in risk management courses at Bordeaux University. This paper describes the SPRITE serious game and the underlying agent-based model, and reports on some lessons learnt from its use in a risk management course.
\end{abstract}

Keywords: Serious game, risk management teaching, ABMS

\section{Introduction}

In their activities, engineers are frequently confronted with various risks, with potentially strong impacts. Teaching risk management to engineering students is therefore essential to prepare them adequately for their future missions. Indeed, [1] present different arguments to justify the importance for engineers to have risk management knowledge and skills: ethics (maintaining the well-being and safety of the public), legal requirements (respecting regulations and laws, integrating new ones or acting on them to improve the legal risk management framework), and financial motivations (minimise cost and optimise financial opportunities). But teaching risk management is also challenging, for different reasons: it appears abstract to students; practical works are complex and expensive to organise; and complex interconnected mechanisms coupling human and technical aspects are difficult to explain. To handle these problems, several authors argue for promoting the use of case studies in risk management teaching: they favour memory to avoid repetition of past failures [2]; they improve student engagement and have a positive and enduring effect on their minds [2]; and they encourage students to integrate multidisciplinary safety considerations in their practices and decision-making [3].

Case study analysis can be efficiently supported by computer simulation, which offers many benefits. Compared to full-scale simulation exercises, it is much less costly, less dangerous, and easier to organise, yet it still allows to discover knowledge by exploring several what-if scenarios before an actual crisis happens, with complete control on all parameters. In particular agent-based simulation represents each actor by an autonomous entity called agent, and explores the global consequences of their local interactions. Participatory simulation is a kind of simulation where human users interact with the simulated world by controlling some of the actors or agents in the system. Participatory simulation is therefore a type of serious games, i.e. games that are used not for entertainment but for learning, training, or understanding mechanisms [4].

In this article, we propose a serious game based on a concrete case study which is exemplary in terms of risk management: SPRITE is built on an agent-based model of the behaviour of the population of an island subject to coastal flooding risk. SPRITE places the player (student) in the role of a local councillor of the Oleron Island (France), to raise their awareness about the risk of coastal flood and the need for a balanced management of that risk. Of course, the target students will probably become engineers rather than politicians, but giving them this role has a double interest: (1) it places them in the position of a decision-maker with a real ability to establish a risk mitigation strategy, and with real responsibilities to assume; and (2) it makes them understand the complexity and the different issues of such decision-making. It is also interesting to offer them a different perspective on risk management, from the point of view of a different actor. Few students will really be in such a position in the course of their professional life, but as engineers they might have to advise deciders. In this context, we argue that playing SPRITE can help students to better understand the responsibilities and constraints of the local authorities, and therefore to better advise them during their career.

The Oleron Island case was also used in LittoSIM [5], a participatory simulation model developed to foster social learning about coastal risk prevention measures with local authorities and managers. Even if SPRITE and LittoSIM 
share the same case-study, their approach and purpose are completely different. LittoSIM is more realistic and more complex than SPRITE, because it is intended for local authorities, who have a strong knowledge of the Oleron territory. It was not designed for teaching, but to make experts reflect on their strategy for the Island. The difference of target player and objectives led to different modeling and game design choices, making the two models very different. In particular they differ on the available player actions, the user interface, the game rules and objectives, the simulation mechanisms and level of realism, etc.

This paper is structured as follows: Section 2 briefly discusses some literature about the use of serious games for teaching in general, and teaching risk management in particular. Section 3 introduces our case study (the coastal flood risk on the Oleron island) and the SPRITE conceptual agent-based model, designed to raise awareness about that risk. Section 4 describes the serious game based on this model, its game design and its implementation. Section 5 introduces the methodology and first results of our evaluation of the use of SPRITE for teaching risk management. Finally, Section 6 concludes and discusses future prospects.

\section{Serious games for teaching}

Serious games span a wide range of applications [6]: training, learning, and raising awareness. Numerous serious games for educational purposes have been developed in the past decade with the advances in technology, making electronic media more accessible [7]. Serious games have several benefits over more classical approaches to teaching. They follow a constructivist logic in which the players build their own knowledge by confronting a problem in a simulated world. A meta-analysis gathering 193 articles about serious games [8] has shown the following benefits: favouring the development of social and human relationships and communication skills; increasing learning motivation, self-esteem and self-confidence, engagement and persistence; developing problem-solving skills; helping learners to structure, build and represent knowledge; and helping learners to integrate information by developing the capability to build links and transfer knowledge from other contexts.

Simulation-based serious games are particularly interesting for raising awareness of various types of risks [9] and engineering complex systems analysis [10]. Simulations are perceived by students as very beneficial regarding comprehension, application, and transfer of knowledge [11]. By being placed in a risky situation and allowed to try several ways of managing it, players can better comprehend risks, their possibility of occurrence, and the consequences of their actions on them. For major risks such as coastal floods, exploring different strategies and their impact in a serious game provides players with some experience, simulated but close to the real world mechanics. Such experience would be hard to acquire from real crises in such a short time, due to the long duration between events, and the stakes involved that prevent from trying random strategies during an actual event.

An important aspect of serious games and participatory simulations is to rely on a pedagogical scenario integrated in the game design to answer a specific pedagogical objective. Moreover, a number of rules must guide the players experience by specifying objectives, conditions of victory or failure, possible interactions with the game and the other players (if any), and mechanisms for the evolution of the game world. These rules can be integrated in the computer model, provided externally (e.g. note card to be referred to when needed), or both. Finally, knowledge delivered in a more classical way (e.g. note cards) is a good complement, with the serious game thus serving as a motivation to acquire knowledge from other sources [12].

\section{Case study}

\subsection{Context: coastal floods on Olron island}

Oleron Island is an island off the Atlantic coast of France, close to La Rochelle. It is the second largest island (174 $\left.\mathrm{km}^{2}\right)$ of Metropolitan France after Corsica; 21000 inhabitants live permanently on the Island. In 2010, the Xynthia storm had a particularly strong impact on the islands of the Atlantic littoral, specifically the island of Olron. Indeed, the combination of a barometric depression (977 hpa), strong South-West wind (over $110 \mathrm{~km} / \mathrm{h}$ with gusts around 140 to $160 \mathrm{~km} / \mathrm{h}$ ), and high tidal coefficient (102) produced a particularly high tide, 50 to $70 \mathrm{~cm}$ over predictions [13], leading to the flooding of a part of the island and important human (53 deaths in France), material (4800 flooded houses, 120 $\mathrm{km}$ of coastline damaged, 40km of departmental roads flooded), and economical (457 M€of public expenses) damage [14]. Before Xynthia, only few extended coastal flood events had happened recently, the last remembered one being the Martin storm in 1999 (and unlike Xynthia its resulting damages were mainly due to the wind rather than coastal flood). The coastal flood risk was therefore largely underestimated by both the local authorities and the population, and as a result mostly ignored in territory planning and management policies [15], leading to an increase of both the risks and the island vulnerability (construction in flood-prone areas, failure to maintain dykes, etc.) [13].

Therefore, the risk of coastal flood became a priority for local councillors of the island of Olron, who began a reflection about the management of this risk, even more so with global warming that leads to an increase in the number of extreme meteorological events and the probability of occurrence of coastal flood [16]. It led to the building of several dykes and other operation in order to increase the protection against the coastal flood. Building a dyke protects the 
littoral from coastal flood but induces maintenance costs, degrades landscape and has a negative impact on fauna and flora. The suddenly change of objective of the local councillor to security has many drawbacks. Indeed, they must meet various competing objectives: ensure the residents safety but also respect a limited budget, preserve fauna and flora, promote the island and make it attractive to tourists and new residents, etc. There is no optimal solution answering all (competing) objectives simultaneously; good management requires a combination of actions regarding the different objectives to reach a balanced compromise between them, but it might be difficult to find for the councillors. Indeed, councillors are not experts of everything, and they tend to favour some solutions at the expense of others depending on their history, convictions, knowledge and culture. Understanding the need to reach a balance is therefore an important stake in order to manage relevantly the territory. The risk management has to be integrated in a more global framework considering also social, environment or economics issues

\subsection{The SPRITE model}

SPRITE seeks to answer that challenge: it is a serious game placing the player (student) in the role of a local councillor to raise his/her awareness about the risk of coastal flood and the notion of balanced management of that risk.

\subsubsection{Parcels and territory.}

The game board is a grid made up of square cells (the Parcel agents). It is built automatically from real Geographical Information System (GIS) data (planimetric and altimetric information, density of buildings, etc.) by an external module (once and for all, to reduce the game initialisation time). The game was designed around this 2D-representation of the Oleron Island. A 3D-representation improves the player immersion (more realistic representation) but makes more complicated the extracting of game principles and mechanisms and limit then the learning [17]. SPRITE is a management game in which understanding the rules and the concepts is more important than immersion; a 2Drepresentation is more relevant in this context. Parcel agents have physical attributes (altitude, water height, dykes, number of residents, etc.) and 4 dynamic values corresponding to the different competing objectives of the mayor (safety feeling, ecological value, housing value and commercial value). Territory agents are composed of a set of parcels and have attributes aggregating the values of their parcels (number of residents, values of the 4 indicators, etc.) as well as specific attributes (tax rate, budget).

\subsubsection{Coastal flood.}

Our flood model is based on [16] and was previously validated [18]. From wind strength and direction, barometric pressure and tidal coefficient, it computes water height and wave height. The coastal flood is then simulated based on an overflow algorithm following 4 stages: initialise weather conditions; propagate water in all directions; propagate waves only in wind wave direction; end coastal flood. Water and wave propagations depend on relative water, wave and dyke altitudes. The algorithm also considers the status and resistance of dykes (which can be damaged by waves, can age over time and can be maintained or repaired by the player).

\subsubsection{Residents.}

The Resident agents are the only autonomous cognitive agents. They have personal preferences for five dimensions (ecology, safety, housing, commercial and tax rate) that they use to assess their satisfaction with their personal situation (values of these indicators for their current parcel). Satisfaction can also be directly influenced by some actions of the mayor (e.g. expropriation) and by the behaviour of other residents. Based on their satisfaction, residents can choose to stay, move to a different parcel, or leave the island altogether. There is also some degree of randomness in their behaviour (residents can randomly leave or arrive for various external reasons, e.g. new job). Finally, residents also compute their political agreement (positive if their satisfaction increased over the mayor's mandate, negative if it decreased) to determine their vote at the next election.

\section{Turning SPRITE into a serious game}

In this section we explain the design of a serious game based on the SPRITE agent-based model and simulation described above. We added an interactive mayor agent controlled by the player, as well as several mechanisms to engage the player and improve learning.

\subsection{Game design}

\subsubsection{Player interactivity: the Mayor agent.}

The student plays the role of the mayor of the territory, and has competing objectives, different actions to fulfil them, and a limited budget (in a virtual money called 'kopecs') that constrains how many actions can be performed. The 
available actions, along with their cost and effects, are divided into three categories: dyke actions (build 3 types of dykes, demolish or repair damaged dykes), planning actions (modify landuse plan, build housing or expropriate and demolish) and territory actions (improve infrastructures and promote tourism, promote local products and industry, and change tax rate). Each of these actions has a mix of positive and negative effects, and progressing one goal often leads to impeding another one.

\subsubsection{Game dynamics.}

The game is based on a triple dynamic (Figure 1): playing, flooding and election.

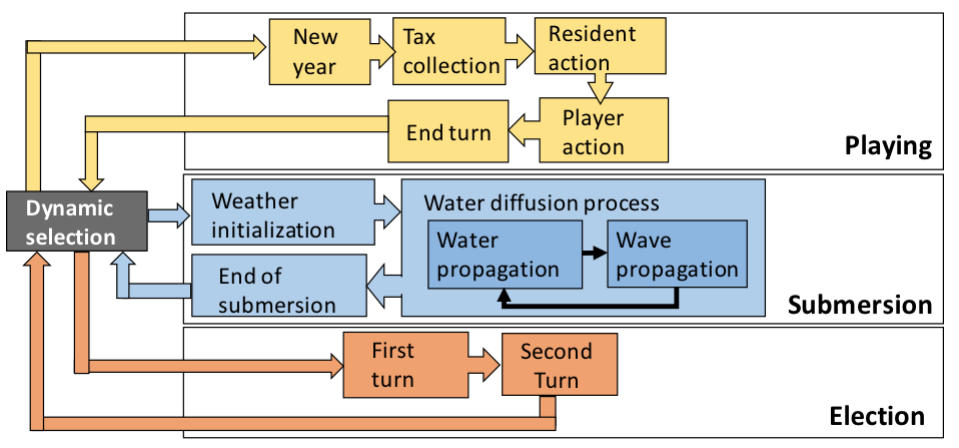

Figure 1: Game dynamics

- Playing dynamic: each turn of the game is one year on the island, and follows the same process: new year start, tax collection, residents actions (stay, leave), player's actions, end of turn.

- Flooding dynamic: if a coastal flood must happen this year (random chance or set in the scenario) it is triggered following this process: weather initialisation, water propagation, wave propagation, end of coastal flood and showing damage map.

- Election dynamic: in election years (set in scenario), an election is triggered in two turns. In the first turn the player is opposed to 4 predefined candidates; the best 2 candidates are opposed in a second turn.

\subsubsection{Engaging mechanisms.}

Beyond interactivity, turning the simulation into a proper serious game requires adding some engaging mechanisms to better immerse the player, improve their learning experience, and maximise acquisition of knowledge, which is the main goal of SPRITE. [19] studied funology, i.e. enjoyment in human-computer interaction, by using Karaseks model of engagement and well-being at work, and found three factors influencing engagement: demands on the worker or player (challenge and surprise but not overwhelming); level of control they have (controlled interaction, timely feedback); and support they receive (social interaction, no isolation). These criteria are also in agreement with [20]s model of motivation in educational games. Due to the variety of players (some prefers competition, others discovery, or interacting with others players...) [21], the gamification to be efficient, must use a combination of elements [22]. In order to match these criteria, we have introduced and combined several engaging elements:

- Demands: actions are constrained by a limited budget, yet sufficient to succeed; elections add some level of randomness and challenge; obtaining a good score requires finding a balance between various indicators;

- Control: the interactive map lets the player control the parcels; the console provides immediate and useful feedback on cost and remaining budget; different pedagogical scenarios of different difficulties can be selected;

- Support: a high-score table allows comparison with other players; the game gains in interest by being played in teams (the players must discuss and reflect together to establish their strategy); future versions will provide multi-player experience by splitting the island into several territories that can compete to attract residents.

These engaging elements are detailed below: game scenarios (Section 4.3.1); constrained budget (Section 4.3.2); elections (Section 4.3.3); and scores (Section 4.3.4).

\subsection{Implementation}

The simulation and serious game are implemented with GAMA, an open-source multi-agent geographical simulation platform [23]. GAMA offers an integrated programming language and development framework, allowing even noncomputer scientists to simply design and maintain elaborated models, with up to several millions of agents. GAMA also provides native management of GIS (Geographical Information Systems) data allowing to integrate geographical data 
files into simulations. Finally, GAMA offers interactive functions (user commands) enabling the use of the participatory dynamics required in SPRITE.

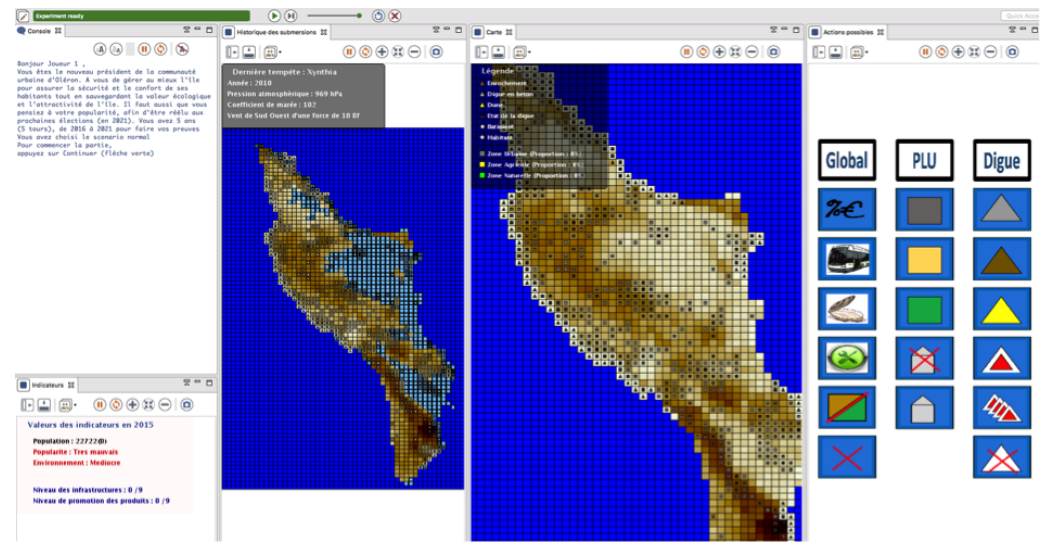

Figure 2: Game interface

Figure 2 shows the game interface. The console (top left) provides the player with useful information during the whole game, guiding her/him during the game. An indicator box (bottom left) displays the current year, the current level of infrastructures and industry, and the values of four indicators: number of residents (and its evolution w.r.t. last year), popularity, environment, and damage from coastal flood. The different action buttons are available on the right, sorted in three actions categories (dyke, planning and territory); the action symbols are explained in the rules provided to the players (on note cards). Finally, the centre screen proposes two maps: the first map records the consequences of the last coastal flood (the light blue parcels are those which were impacted by this flood) to allow the player to build their strategy based on recent events; the second map is the game board and supports all the actions on parcels (i.e. dyke and planning actions).
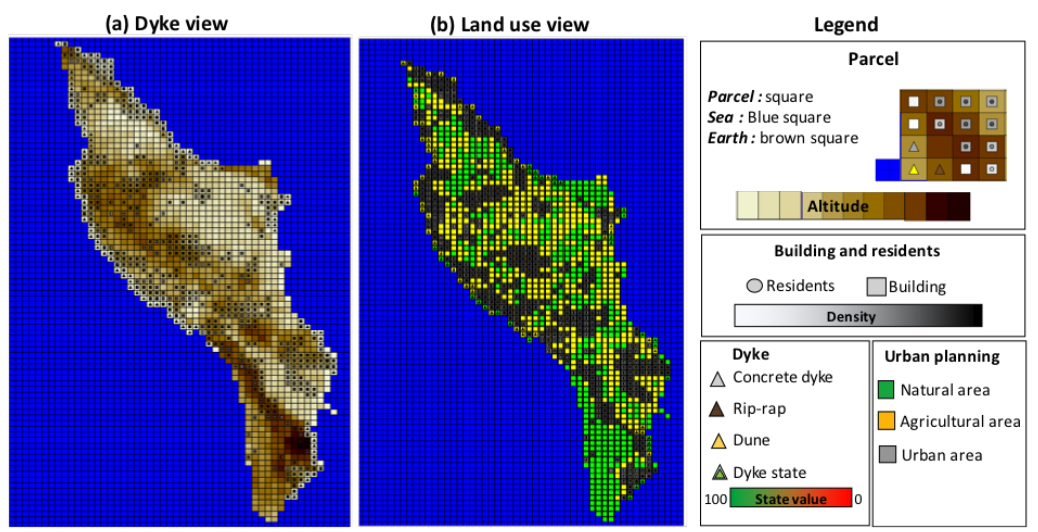

Figure 3: Game board map

Two views on the game board map (Figure 3) are available: Dyke view and Land use view. The player can switch from one view to another at any moment by pressing a button (Change view button) in order to choose the displayed information. On the game board map, squares represent the buildings (darker squares for higher construction density). Circles represent the population (darker circles for more densely populated parcels). On the Dyke view (a), colour indicates parcel altitude (the darker the higher) and triangles of different colours represent dykes of different types. Finally, the three colours of the Land use map (b) indicate the type of parcel (grey: urban, yellow: agricultural, green: natural).

\section{Evaluation of SPRITE for teaching}

The SPRITE serious game was beta-tested by a small number of heterogeneous participants in order to calibrate the rules, scoring and overall balance of the game, and to improve game design and engagement (e.g. adding elections). The game was then used with the specific purpose of teaching risk management to students. The paragraphs below describe the design of a pedagogical scenario, our evaluation methodology and our first results. 


\subsection{Designing the pedagogical scenario and sequence}

As exposed in the introduction, SPRITE was developed with a pedagogical perspective, and enables to propose specific pedagogical scenarios. Creating a relevant scenario is a major issue, and is key to successful learning. Scenarios must be designed according to the notion to learn. In this paragraph we propose a specific pedagogical scenario called Rim (for Risk management).

\subsubsection{Notions to learn.}

The principle of the Rim scenario is to place the student into the position of the Olron mayor during the last 15 years, in order to make him live the same course of events as the real mayor of Olron. We assume that it allows the student to learn the same lessons that were learnt by the local authorities from the real events, and to guide the player to a balanced management of the territory risk. Students are thus expected to learn various concepts and notions: territory risk, vulnerability of a territory, resilience, risk perception, risk culture, multi-criteria analysis and balanced management.

\subsubsection{Pedagogical scenario.}

The Rim scenario is composed of three distinct parts corresponding to three successive periods; each contains 5 turns (5 years) and finishes by an election.

1. Period 1 (2004-2008) Prologue: the Rim scenario places the player in 2004, at the beginning of a new mandate. A message informs the player of the importance to grow the population, to ensure the economic development of the island, and to improve their popularity in order to ensure their re-election. During this period, no coastal flood occurs, and no message or warning is given to the player regarding coastal flood risk. The player is encouraged to ensure a good development of the island, therefore increasing (unknowingly) the vulnerability of the island to coastal floods (new buildings near the coast-line, no dyke maintenance, etc.). To ensure the continuity of the game, the player should be re-elected at the end of this first period. If the player was to lose the election, the model falsifies the result and makes him win with $50.01 \%$ of votes in the second turn.

2. Period 2 (2009-2013) Xynthia: after the first period which was positive for the player, the second period begins by a coastal flood: the simulation of Xynthia. The more the player increased the territorial vulnerability in the first period, the more important the damage will be. A message now informs the player of the importance of the damage, and of the necessity to ensure the safety of the residents. The expected behaviour of the player in response to this consists in building numerous dykes and limiting urban areas in vulnerable parcels, leading to expropriations. The popularity of the player should decrease during this period as a result. A medium coastal flood then occurs again in 2013 in order to test the island protection against coastal floods. Most players should successfully be re-elected (if the protection against the second coastal flood was correct, and if they used part of the budget to satisfy residents) but more tightly (around 50-55\% of votes). Again to ensure continuity, in case of a defeat the results are automatically falsified to make the player pass with $50.01 \%$ of votes in the second turn.

3. Period 3 (2014-2018) Wise: the limited victory of the player in the second period should alert them on the importance of the other issues than safety alone. A message informs the player of the importance of the environment, the economy, and residents satisfaction. The player is encouraged to have a wide (and wise) management of the island. Two coastal floods occur during this period: a small/medium intensity flood in 2015 , and a medium/strong intensity flood in 2017 , so safety should not be neglected but the other criteria either. The period finishes by a last election which, this time, is not falsified. The player then receives their final score.

\subsubsection{Pedagogical sequence.}

The Rim scenario was conceived for teaching risk management to French Master students in civil engineering, but it could also be used for other types of students or in other contexts. About 20 students in the class work in pairs under the guidance of one teacher. The pedagogical sequence is composed of four phases. The first phase is the presentation of the game: the teacher exposes the learning process, and the principle and rules of the game. The second phase consists in playing the game: students play the Rim scenario of SPRITE in pairs (each pair on one computer), and discuss strategy and choices of actions together. Exchanges between different groups are not forbidden but not encouraged, and limited by the competitive aspect of the game (each group should try to get the best final score), which ensures that different strategies can be explored, thus enriching the post-game discussions. The teacher answers potential questions and encourages students to reflect on their strategy, but without guiding their choices. The duration of each turn is limited to 10 minutes for the first turn (to let the students understand the interface) and 5 minutes for each subsequent turn. The total duration of this second phase is 80 minutes. The third phase is a debriefing organised after the end of the game in order to allow students to share their game experience and their reflection. These discussions are guided by the teacher, ensuring that all students can equally speak, and orienting questions and reflections towards the notions to learn. This debriefing is extremely important to ensure a good understanding of the game issues, and to make the 
learning deep and durable [24]. In a last phase, the teacher exposes, in a normal lecture, the different notions that were to be learnt, illustrated with examples from the game experience.

\subsection{Experimentation}

\subsubsection{Experimentation methodology.}

The University of Bordeaux has been offering since 2010 a course on risk management aimed at engineering students in the Master of Geology and Civil engineering. Our experimentation was conducted with a group of 14 students from this risk management course. To measure the learning impact of SPRITE, the following method was used:

1. at the beginning of the course, students first have to fill in a questionnaire about risks, to evaluate prior knowledge;

2. students then play with SPRITE following the pedagogical sequence above (presentation, playing, discussion);

3. one month later, students fill in the same questionnaire about risk as they did before, in order to evaluate their progress.

The two sets of questionnaires are then made anonymous, mixed, and marked by a teacher who does not participate in SPRITE. In order not to influence his marking, he does not know if the questionnaires were filled in before or after using SPRITE.

\subsubsection{Results.}

Figure 4 exposes the student results on the tests performed before and after the pedagogical sequence. The increase in students' marks is noticeable (median from C- to C+), showing that SPRITE allows students to learn about risk and risk management.

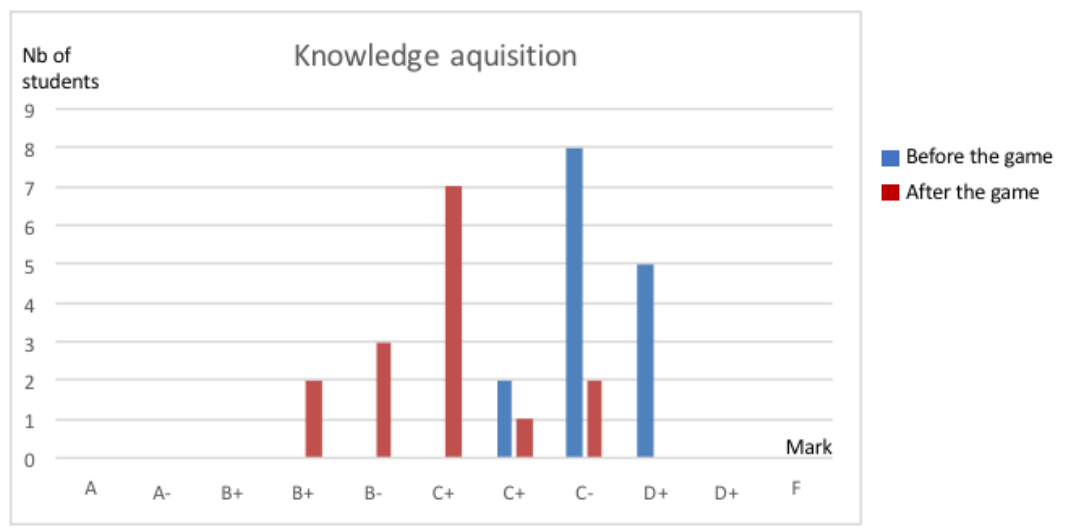

Figure 4: Students' marks in the test before and after using SPRITE

However, our experiment does not allow to compare this pedagogical sequence with a classical course of an identical duration. Indeed, it was a first pedagogical experience and we had only few students, so all of them followed the same pedagogical sequence, and we have no comparison point. Another well-known advantage of serious games, persistence of acquired knowledge [25], cannot be assessed either with this single experiment. It would be an interesting aspect to study in subsequent years, by having the students answer the same test again, one year after the course. Therefore, measuring the exact added value of SPRITE is still an on-going work, which will be pursued in the future.

\subsubsection{Player behaviour.}

During the game, all the actions and indicators values were recorded for each student group. It enables to check the consistency between expected behaviour and real player behaviour (Figure 5). The expected behaviour is:

(a) improve popularity/environment in the first period by working on urban plan and improving infrastructures,

(b) perform dyke actions in reaction to Xynthia in the second period, and

(c) adopt a more balanced strategy in the third period. 


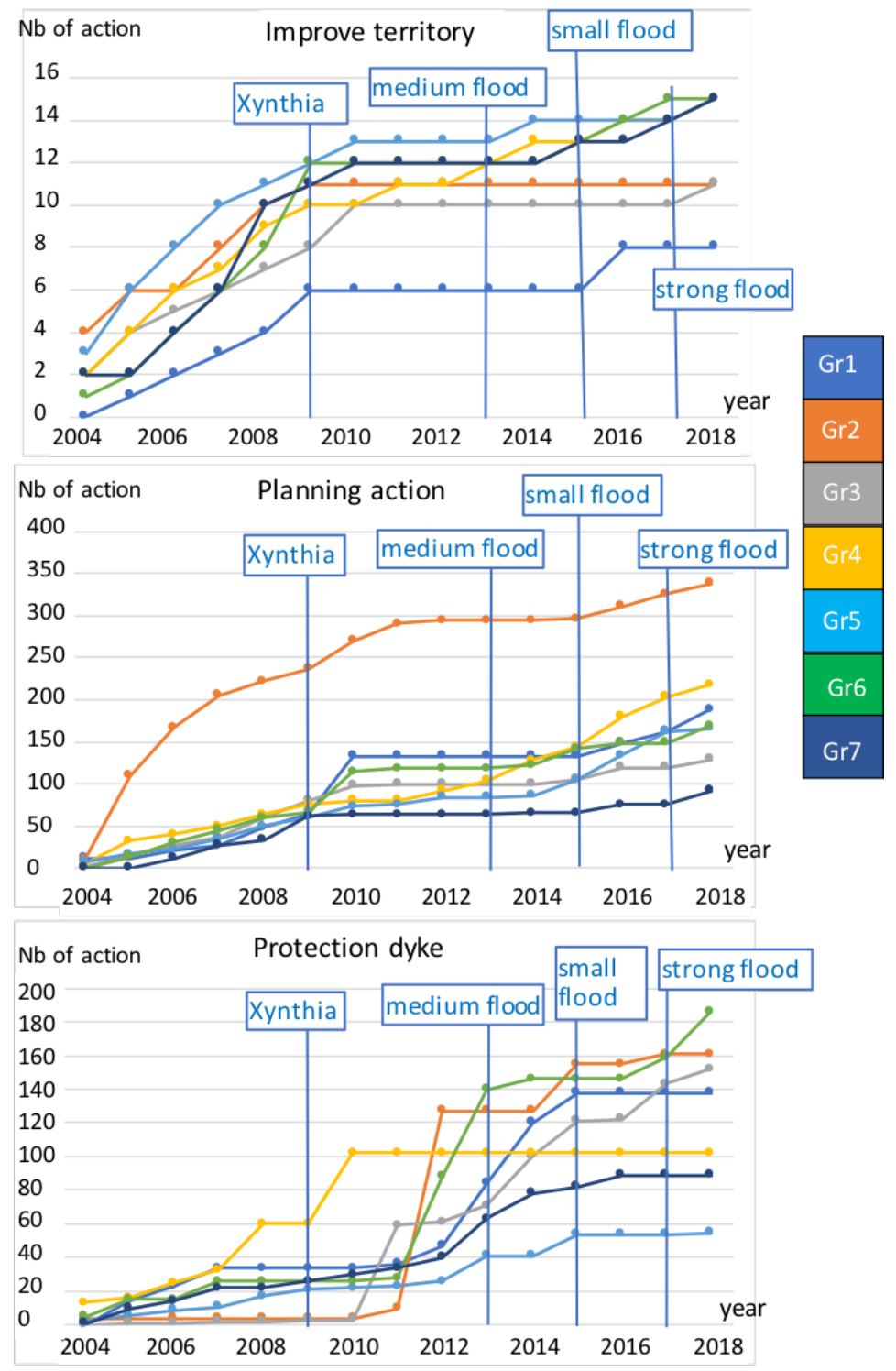

Figure 5: Player actions 
During the first period, most players favoured actions improving territory and infrastructures. They also made planning actions in order to increase urban and natural areas. Group 2 (orange) has particularly modified the urban planning by creating an important urban area close to the sea, and natural areas in the South of the island. Group 4 (yellow) has anticipated the possibility of a flood by building some dykes already in the early years.

During the second period, just after the occurring of the Xynthia storm and its induced flood, most players used the totality of their budget (or almost) to build dykes; we enter a hard defence period. Some players had to wait 1 or 2 years before the construction of dykes, because the damage from Xynthia floods was so important that they first spent all their budget in repairs. Group 5 (light blue) limited the number of dykes built, and continued to improve the territory and infrastructures despite the danger. Group 4 (yellow) who had already anticipated the flood risk, just built several new dykes.

During the last period (2014-2018), the players mixed their actions: they built some dykes, made some planning actions, and slightly improved their territory and infrastructures.

The players' behaviour was therefore mostly consistent with our expectations, facilitating the knowledge acquisition during the game, the post-game discussion, and the final course.

\subsubsection{Scores analysis.}

The score of the seven groups varies from 4830 (Low score category) to 5450 (High score category) as exposed in Figure 6. The five other groups have an average score (between 5000 and 5300).

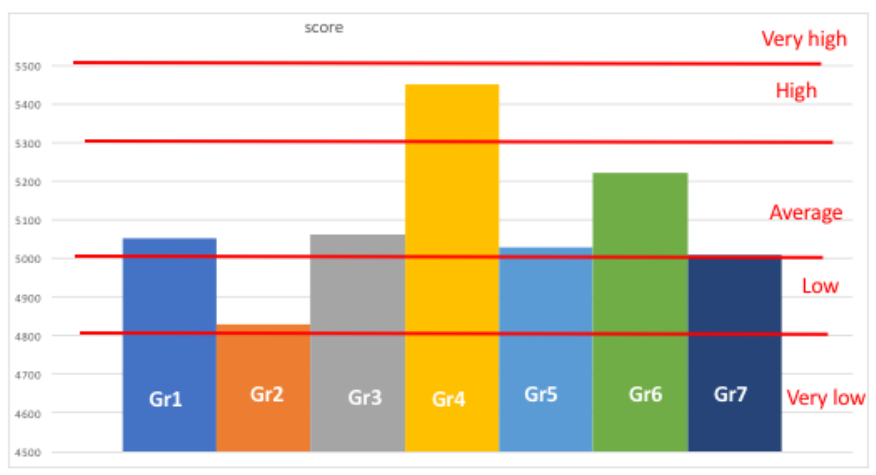

Figure 6: Final score of the different groups

These scores can be put in parallel with players' strategy, and refined according to the three sub-criteria (Environment, Popularity and Population). Comparing the strategies of Gr2 (the lowest score) and Gr4 (the highest score) is interesting: the evolution of their detailed scores on the 3 sub-criteria is shown in Figure 7 . In the first period, Gr2 made a high number of modifications of the urban plan: they created an important urban area, and compensated it by also creating many natural areas. During the same period, Gr4 also created some natural areas, but also built dykes to protect more vulnerable urban areas. It results in two close scores on the three sub-criteria at the end of the first period (with an advantage on environment to Gr2 and on popularity to Gr4). But the territory of Gr2 was more vulnerable and was largely more impacted by Xynthia at the beginning of the second period. The limited damage was quickly repaired by Gr4, while it took Gr2 three years to repair all damage with a limited budget. The duration of this deteriorated situation (unrepaired damage) has strong consequences on player's popularity: indeed the population does not appreciate the deteriorated infrastructures, unlivable buildings, damaged dykes, etc. As soon as Gr2 finished repairing damages, they invested most of their budget to build new dykes. To counterbalance these constructions, they also planned natural areas, explaining their gain on the environmental criterion. However, the vulnerability of their territory made it difficult for them to establish a good trade-off between the different criteria in the last period. They finally built more dykes than Gr4, but their territory remained unsafe because of the presence of buildings in vulnerable areas. This situation impacted their popularity and as a result their population (unsatisfied residents can move out). On the contrary, Gr4 exploited their initial advantage and kept improving both their territory and the environment in the last period.

Even though Gr2's final score is largely lower than Gr4's, it does not mean a lower acquisition of knowledge from the course. On the contrary, they could learn from their mistakes, and gain a better understanding of what to do and 


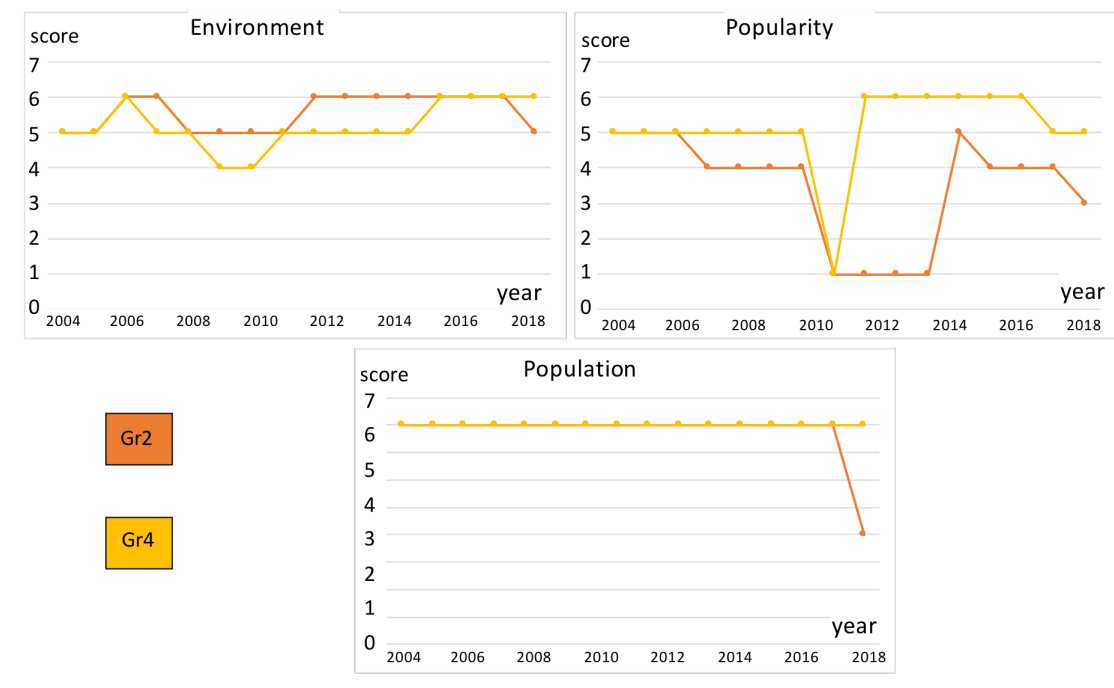

Figure 7: Detailed scores on the sub-crcomp-subiteria for Groups 2 and 4

what to avoid. However, we cannot verify this assumption because the tests were anonymous and cannot be linked with game scores.

\subsubsection{Feedback from students.}

In order to get feedback about students' opinions about SPRITE, we have also asked the students to answer some questions about the SPRITE serious game itself, right after playing it. They have given marks between 1 (worse) and 10 (best) to various indicators about the game (immersion, pleasantness, quality of the interface, appropriateness of the game duration, difficulty), about themselves (previous experience with serious games, understanding of the rules, motivation to perform well in the game, understanding of the notions taught), and about the pedagogical impact (quality of the pedagogical sequence, will to use serious games in learning). Figure 8 illustrates the scores on 5 of these indicators with minimum, median, and maximum mark.

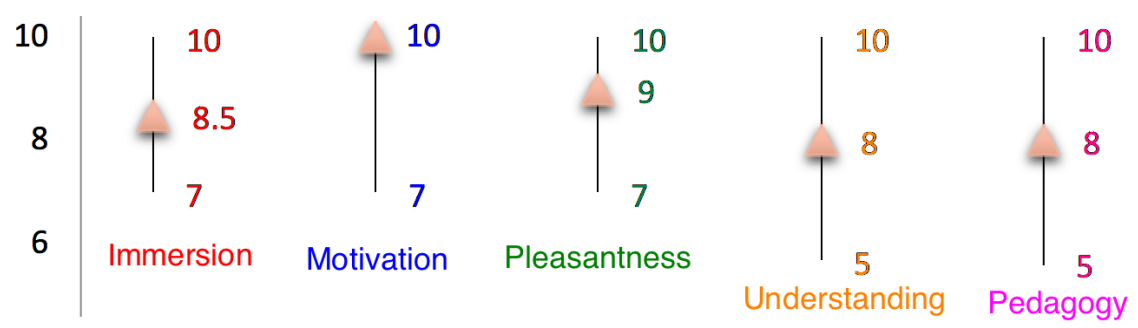

Figure 8: Evaluation (min, median, max) of 5 indicators (marked from 1 to 10) by students after playing with SPRITE.

These scores, as well as qualitative feedback from the students, show that SPRITE was well received by the students, most of whom would want to use serious games again in their studies. Despite a quite simple interface (which received an average score of 7.5), students reported good immersion in the game (average score 8.6) which was found to be pleasant to play (average score 8.8) and motivating (average score 9.4). Students also reported a strong feeling of having understood the notions taught. However, students also acknowledged that the game alone is not sufficient but must be accompanied by a more traditional course and a discussion of the notions learnt (importance of the debriefing). This is in agreement with [12] who insists that knowledge delivered in a more classical way completes the gaming experience, and turns the game into a motivation factor to acquire knowledge.

\section{Conclusion}

SPRITE, a simulation-based serious games, was designed for risk management teaching and to raise awareness of territory risks. It allows the user to play the role of the mayor and manage the island of Olron for a number of years, with the mission of finding an appropriate balance between popularity, economy, safety and ecology. SPRITE is a central piece of a pedagogical sequence allowing students to learn and think about different notions: territory risk, 
vulnerability of a territory, resilience, risk perception, risk culture, multi-criteria analysis and balanced management. The model is fully implemented in GAMA and the game is already playable. It was used at the University of Bordeaux in a course on risk management dedicated to engineering students in the Master of Geology and Civil engineering. The evaluation of engagement with the game and learning from playing it is still preliminary but encouraging. Short term future work will mainly be dedicated to pursuing this evaluation. Longer term prospects include several improvements of the model and the interface. In particular, we plan to refine the mechanisms involved in the residents decision-making, by taking into account more factors, including emotions (fear of the next flood, anger at the mayor after a relocation, etc). However, the results of this experimentation were already promising and the experimentation will be renewed the following years.

\section{References}

[1] Amyotte PR and McCutcheon DJ. Risk management an area of knowledge for all engineers. Technical report, Research Committee of the Canadian Council of Professional Engineers, 2006.

[2] Saleh JH and Pendley CC. From learning from accidents to teaching about accident causation and prevention: Multidisciplinary education and safety literacy for all engineering students. Reliability Engineering and System Safety 2012; 99: $105-113$.

[3] Hale A and de Kroes J. System in safety 10 years of the chair in safety science at the delft university of technology. Safety Science 1997; 26(1): 3-19.

[4] Michael D and Chen S. Serious games: Games that educate, train, and inform. Boston, MA.: Thomson Course Technology, 2006.

[5] Becu N, Amalric M, Anselme B et al. Participatory simulation to foster social learning on coastal flooding prevention. Environmental Modelling and Software 2017; 98(Supplement C): 1 - 11.

[6] Westera W. How people learn while playing serious games: A computational modelling approach. Journal of Computational Science 2017; 18: 32-45.

[7] Madani K, Pierce TW and Mirchi A. Serious games on environmental management. Sustainable Cities and Society 2017; 29: $1-11$.

[8] Sauve L, Renaud L and Gauvin M. Une analyse des crits sur les impacts du jeu sur lapprentissage. Rev Sc duc 2007; 33(1): $89-107$.

[9] Crovato, S et al. Food safety and young consumers: Testing a serious game as a risk communication tool. Food Control 2016; 62.

[10] Bekebrede G, Lo J and Lukosch H. Understanding complexity: The use of simulation games for engineering systems. Simulation 83 Gaming 2015; 46(5): 447-454.

[11] Riemer V and Schrader C. Learning with quizzes, simulations, and adventures: Students' attitudes, perceptions and intentions to learn with different types of serious games. Computers and Education 2015; 88: 160-168.

[12] Wouters P, Spek E and Oostendorp H. Current practices in serious game research: A review from a learning outcomes perspective. In Games-Based Learning Advancements for Multi-Sensory Human Computer Interfaces: Techniques and Effective Practices. IGI Global, 2009. pp. 232-250.

[13] Vinet, $\mathrm{F}$ et al. Le processus de production du risque "submersion marine" en zone littorale : l'exemple de Xynthia. NOROIS $2012 ; 222: 11-26$.

[14] Bersani, C and coll. Tempte Xynthia : retour d'exprience, valuation et propositions d'action. Technical report, Ministre de l'cologie, du dveloppement durable et de la mer ; Conseil gnral de l'environnement et du dveloppement durable ; Insp. gn. des finances ; Insp. gn. de l'administration, 2010.

[15] Duvat-Magnan V. Les impacts de la tempte Xynthia sur les plages de l'le d'olron : les ralits du terrain. Technical report, Institut du Littoral et de lEnvironnement, 2010.

[16] Le Cozannet, G et al. Evaluating uncertainties of future marine flooding occurrence as sea-level rises. Environmental Modelling and Software 2015; 73: 44-56.

[17] Koops MC, Verheul I, Tiesma R et al. Learning differences between 3d vs. 2d entertainment and educational games. Simulation \& Gaming 2016; 47(2): 159-178.

[18] Adam C, Taillandier F, Delay E et al. SPRITE, participatory simulation for raising awareness about coastal flood risk on the oleron island. In ISCRAM-med, LNBIP, volume 265. Springer, 2016. pp. 33-46.

[19] Brandtzaeg PB, Folstad A and Heim J. Enjoyment: Lessons from karasek. In Funology: From Usability to Enjoyment, HCI, volume 3. Springer, 2006. pp. 55-65.

[20] Garris R, Ahlers R and Driskell JE. Games, motivation, and learning: A research and practice model. Simulation and Gaming 2002; 33(4): 441-467.

[21] Nacke LE, Bateman C and Mandryk RL. Brainhex: Preliminary results from a neurobiological gamer typology survey. In Anacleto JC, Fels S, Graham N et al. (eds.) International Conference on Entertainment Computing (ICEC). Berlin, Heidelberg: Springer, 2011. pp. 288-293.

[22] Landers RN. Developing a theory of gamified learning: Linking serious games and gamification of learning. Simulation 8 Gaming 2014; 45(6): 752-768. 
[23] Grignard A, Taillandier P and Gaudou B. GAMA 1.6: Advancing the art of complex agent-based modeling and simulation. In PRIMA, LNCS, volume 8291. Springer, 2013. pp. 117-131.

[24] Crookall D. Serious games, debriefing, and simulation/gaming as a discipline. Simulation Es Gaming 2010; 41(6): 898-920.

[25] Crocco F, Offenholley K and Hernandez C. A proof-of-concept study of game-based learning in higher education. Simulation Es Gaming 2016; 47(4): 403-422. 